\title{
Video Animasi Stop Motion Sebagai Media Pembelajaran Pada Kampanye Pengenalan Tertib Berlalu Lintas Bagi Remaja Pengendara Sepeda Motor
}

\author{
Purwanti, R. ${ }^{1}$, Natanael, R. ${ }^{1}$ \\ Program Studi Desain Komunikasi Visual \\ Universitas Pembangunan Jaya \\ retno.purwanti@upj.ac.id
}

\begin{abstract}
There are various campaign methods to increase traffic-rules awareness among young people such as banner, poster, and other print media. A different campaign approach for increasing traffic-rules awareness to junior high school students is using a video format with stop motion animation style. The video format approach is more popular than the print media counterpart because the stop motion animation can serve as an entertaining media with strong audio visual which attract young people. Another benefit of the stop motion animation is that it can be used to introduce prominent characters into the storyline. The research method used here is the combination of literature study, observation and questionnaire
\end{abstract}

Keywords : Video, Animation, Stop Motion, Campaign, Traffic

\begin{abstract}
Abstrak :Format video dengan gaya animasi stop motion sebagai media kampanye penyadaran tertib lalu lintas berkendara roda dua bagi remaja khususnya pelajar SMP menjadi pilihan karena media ini lebih populer dikalangan remaja dibandingkan bentuk kampanye berupa spanduk, poster maupun media cetak lainnya. Kelebihan media ini selain lebih menghibur dengan output audio visualnya juga dapat menonjolkan karakter tiap tokohnya. Metode yang digunakan dalam kampanye ini adalah observasi, kuesioner dan studi literatur.

Kata Kunci : Video, Animasi, Stop Motion, Kampanye, Lalu Lintas
\end{abstract}

\section{PENDAHULUAN}

Terbatasnya pilihan transportasi umum khususnya didaerah pinggiran ibukota seperti Bintaro, Tangerang Selatan pada akhirnya membuat kendaraan bermotor roda dua atau yang lebih dikenal dengan sepeda motor menjadi pilihan favorit sebagai alat mobilitas. Cepat dan irit menjadi alasan utama banyak kalangan masyarakat memilih moda transportasi sepeda motor, termasuk kalangan pelajar SMP dengan rata- rata usia mereka yang masih berkisar antara 13 hingga 15 tahun yang sebenarnya belum memenuhi syarat untuk mengendarai sepeda motor.

Sebagaimana kita ketahui bersama bahwa syarat utama untuk dapat mengendarai kendaraaan bermotor baik roda empat maupun roda dua adalah memiliki SIM (Surat Ijin Mengemudi) yang salah satu prasyarat untuk mendapatkannya adalah telah berusia 16 tahun, seperti yang tercantum dalam UU no.02 tahun 2002 Pasal 217 (1) PP 44 / 93 yang mensyaratkan batas usia pemohon SIM golongan $\mathrm{C}$ adalah minimal berusia 16 tahun.

Berdasarkan data yang didapat dari http://ntmcpolri.info (2016) menyebutkan data pelanggaran lalu lintas tertinggi di pegang oleh remaja. Adapun pelanggaran tersebut diantaranya ketiadaan pemilikan SIM (Surat Ijin Mengemudi), tidak adanya kelengkapan surat-surat kendaraan, melanggar marka jalan, hingga melawan arus. 
Berdasarkan hasil kuisioner yang disebarkan pada 50 pelajar SMP Ricci II yang terletak di Pondok Aren, Bintaro Tangerang Selatan, dengan usia responden 13 - 15 tahun, sebagai studi kasus maka diperoleh data sebagai berikut :

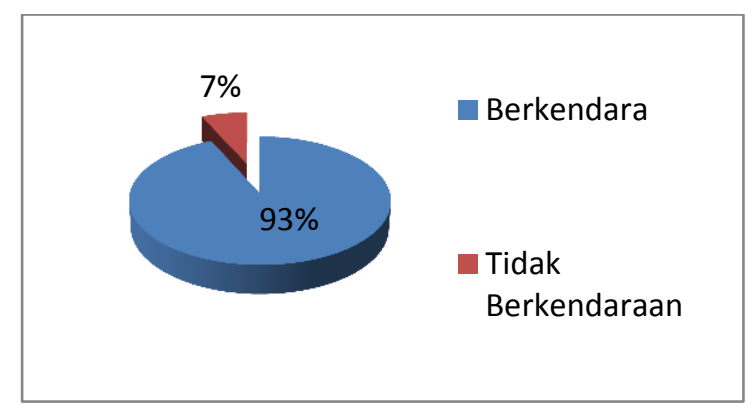

Gambar 1. Siswa yang membawa kendaraan

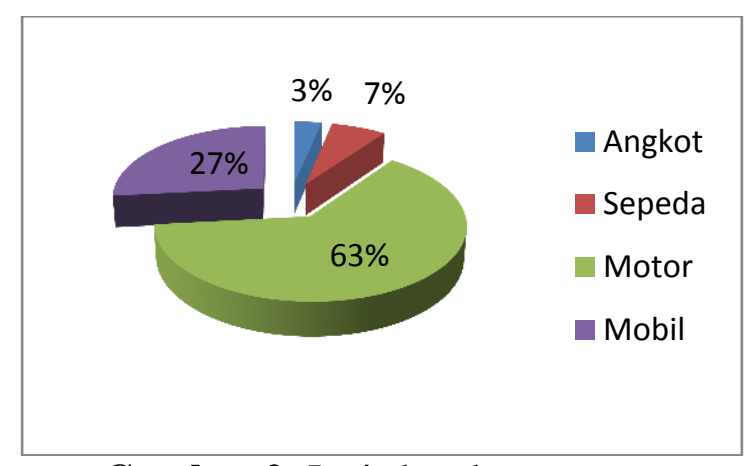

Gambar 2. Jenis kendaraan yang digunakan

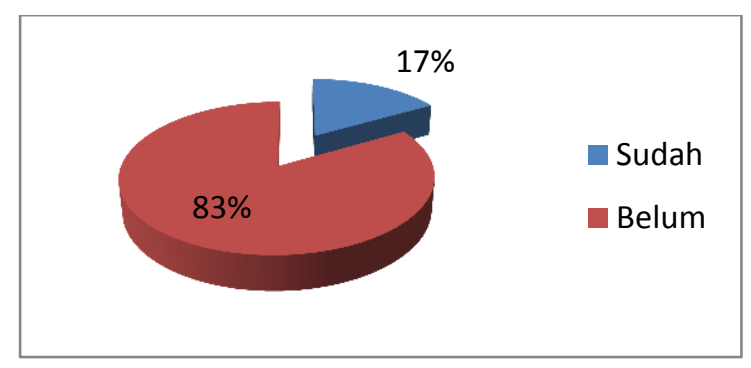

Gambar 3. Pengetahuan tentang standar keamanan berlalulintas

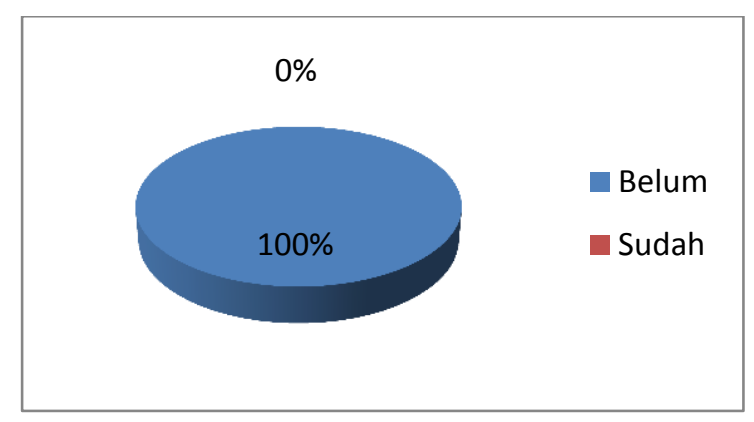

Gambar 4. Kepemilikan SIM
Berdasarkan data yang dikutip dari http://ntmcpolri.info (2016) menyebutkan data pelanggaran lalu lintas tertinggi di pegang oleh pelajar pada usia 16-30 tahun. Adapun pelanggaran tersebut diantaranya ketidak pemilikan SIM (Surat Ijin Mengemudi), tidak adanya kelengkapan surat-surat kendaraan, melanggar marka, dan melawan arus.

Menurut Sri Rumini dan Siti Sundari (2004:53) masa remaja adalah peralihan dari masa anak dengan masa dewasa yang mengalami perkembangan semua aspek/fungsi untuk memasuki masa dewasa. Masa remaja berlangsung antara umur 12 tahun sampai dengan 21 tahun. Rentang waktu usia remaja ini biasanya dibedakan atas empat fase, yaitu 10-12 tahun (masa pra remaja), 12 - 15 tahun (masa remaja awal), 15 - 18 tahun (masa remaja pertengahan), 18 - 21 tahun (masa remaja akhir).

Tentunya bukan tanpa alasan undang - undang menentukan perlunya batasan minimal usia, sebab umumnya usia remaja masih memiliki karakter yang labil atau belum memahami etika dan aturan dalam berlalu lintas dengan baik. Pada masa ini, kebanyakan dari mereka lebih mengedepankan sifat individualisme dan egoisme yang tinggi dan sering tidak memperdulikan hak orang lain di jalan. Pemahaman dan kematangan psikologis yang kurang matang atau masih labil ini di usia remaja akan beresiko menyebabkan kecelakaan saat berkendara. Kondisi psikologis seseorang pada saat remaja memiliki karakteristik yang labil, sulit dikendalikan, melawan dan memberontak, memiliki rasa ingin tahu yang tinggi, agresif, mudah terangsang serta memiliki loyalitas yang tinggi (Sarwono, 2006).

Pelanggaran paling mendasar dari remaja pengendara sepeda motor adalah dari sisi batas minimal usia yang belum terpenuhi, namun ini bukan satu-satunya jenis pelanggaran yang mereka lakukan. Menaiki sepeda motor tanpa helm, 
berpenumpang lebih dari dua orang, mengedarai motor secara ugal - ugalan merupakan realita yang sering dijumpai di jalan raya. Hal ini tidak hanya membahayakan diri mereka sendiri namun juga mengancam nyawa orang lain.

Berdasarkan fakta - fakta tersebut telah banyak dibuat kampanye yang menyuarakan tentang tertib lalu lintas, meski tidak secara khusus membidik sasaran remaja sekolah menengah tingkat pertama. Umumnya kampanye yang dilakukan hanya berupa slogan - slogan yang dibentangkan dalam spanduk dan kurang mendapat perhatian terutama dari kalangan remaja, sehingga dirasakan perlu dibuat kampanye yang lebih menarik sekaligus komunikatif bagi remaja.

Metode yang digunakan pada kampanye ini adalah metode kualitatif. Dengan menggunakan model kampanye Ostergaard, seperti yang dijelaskan oleh Venus, A. (2009) dalam bukunya "Manajemen Kampanye" dilakukan pengumpulan data untuk menjawab cara yang tepat dalam memberikan informasi terhadap etika berkendara yang baik melalui sebuah video animasi stop motion pada remaja.

\section{PEMBAHASAN}

Berkaitan dengan perkembangan psikologi remaja serta pendekatan yang perlu dilakukan untuk menentukan komunikasi yang tepat dengan mereka, Gunarsa berpendapat bahwa sumbersumber utama dari informasi mengenai arti dan nilai-nilai adalah berasal dari orang tua, guru-guru, dan pemimpin-pemimpin kelompok remaja. Pergaulan menempati urutan tertinggi sebagai usaha remaja untuk membebaskan diri dari pengaruh orang tua. Kadang-kadang keputusan yang menentukan kehidupan diperoleh dari pengaruh pembicaraan intim dengan teman-teman. (Gunarsa, 2008).

Meskipun figur orangtua maupun orang yang disegani oleh remaja tetap dibutuhkan, namun tampaknya figur teman tetap menjadi lebih dominan dan membawa arti penting bagi remaja, sehingga perlu dicermati kegiatan apa saja yang mereka lakukan saat berkumpul bersama.

Dari sekian banyak aktivitas yang dilakukan oleh kelompok remaja, menonton merupakan satu kegiatan yang disukai oleh mereka diwaktu luang. Jenis tayangan yang ditonton pun kini tak sebatas hanya layar kaca dan layar lebar. Seiring dengan perkembangan teknologi, media tayangan yang berisi konten untuk remaja pun makin bervariasi, salah satunya adalah video.

Video berasal dari bahasa Latin, video-vidivisum yang berarti melihat (mempunyai daya penglihatan) dapat melihat. Video merupakan salah satu jenis media audio visual. Media audio visual adalah media yang mengandalkan indera pendengaran dan penglihatan. Media ini memiliki fungsi yang sangat berguna bagi dunia pembelajaran dan pendidikan seperti yang dikatakan oleh Hamanik (2008) bahwa fungsi media pembelajaran yaitu:

1. Untuk mewujudkan situasi pembela jaran yang efektif.

2. Penggunaan media merupakan bagian internal dalam sistem pembelajaran.

3. Media pembelajaran penting dalam rangka mencapai tujuan pembelajaran.

4. Penggunaan media dalam pembelajaran untuk mempercepat proses pembela jaran dan membantu siswa dalam upaya memahami materi yang di sajikan oleh guru dalam kelas.

5. Penggunaan media dalam pembelajaran di maksudkan untuk mempertinggi mutu pendidikan.

Kata animasi (animate) berasal dari kata kerja Latin yaitu animare, yang berarti "membuat jadi hidup atau mengisi dengan nafas", Jean Ann Wright. Animasi adalah usaha untuk membuat presentasi statis menjadi hidup, Vaughan (2004).

Jenis - jenis animasi :

Animasi 2D, jenis animasi yang lebih dikenal dengan film kartun pembuatannya menggunakan teknik animasi hand draw 
atau animasi sel, penggambaran langsung pada film atau secara digital.

Animasi 3D, merupakan pengembangan dari animasi 2D yang muncul akibat teknologi yang sangat pesat. Dan terlihat lebih nyata dari pada 2D.

Animasi stop motion, merupakan jenis animasi yang merupakan potonganpotongan gambar yang disusun sehingga bergerak. Terdapat 12 prinsip teknis animasi dalam pembuatan animasi yang harus dimiliki oleh seorang animator, selain memiliki feeling yang kuat mengenai timing, pergerakan, pengamatan dan tingkah laku. Animator harus menjadi seorang aktor, memiliki perasaan yang peka, dan logika agar dapat membuat sesuatu menjadi hidup dan alami. Prinsipprinsip tersebut antara lain (George Maestri, 2006):

\section{Timing}

Timing yaitu dapat diartikan sebagai acting serta timing pergerakan satu karakter dalam satu scene. Sehingga gerakan animasi dapat terlihat tidak kaku atau bahkan sangat lamban.

2. $\operatorname{Arc}$

Arc yaitu gerakan yang membentuk garis lengkung yang dialami dalam dunia. Tiap benda mempunyai gaya atau kekuatan, kecuali benda yang sifatnya mekanis atau tidak alami.

3. Squash and Stretch

Squash and Stretch yaitu dapat diimplementasikan dalam beberapa proses perubahan bentuk pada kulit dan otot, lompatan, morphing, pengaruh berat, simulasi objek-objek dynamic.

4. Anticipation

Anticipation yaitu gerakan animasi selalu memiliki tahap persiapan ketika melakukan sebuah aksi atau gerakan.Gerakan yang menujukkan gerakan awal atau persiapan yang dilakukan.

5. Esay In and Esay Out

Esay In and Esay Out yaitu prinsip yang berhubungan dengan aksele rasi ketika objek mengalami percepatan dan perlambatan ketika mengalami pergerakan.

6. Secondary Action

Secondary Action yaitu membuat animasi terlihat lebih alami dan menarik. Merupakan gerakan pen dukung dari gerakan utama yang mengalami pergerakan.

7. Follow Through and Overlapping Follow Through and Overlapping yaitu reaksi yang terjadi atau gerakan overlap sebuah karakter animasi setelah melakukan animasi utama atau gerakan utama.

8. Staging

Staging yaitu membuat sebuah gerakan sehingga mudah di mengerti. Menggambarkan mood, aksi dan posisi suatu karakter animasi.

9. Straight Ahead Action and Pose to Pose Action

Straight Ahead Action and Pose to Pose Action yaitu standar teknik animasi dengan merencanakan struktur gerakangerakan yang terjadi melalui pose-pose kunci (key pose). Straight ahead action adalah teknik animasi dengan meng gerakan karakter untuk per framenya hingga selesai.

10. Personality/Appeal

Personality/Appeal yaitu karakter yang memiliki personality atau kepribadian akan mampu menghubungkan emosi antar karakter tersebut dengan penonton. Kompleksitas dan konsistensi gerakan adalah dua elemen daya tarik karakter yang dapat dengan mudah dikembangkan di dalam komputer animasi 3D hingga mampu mendefinisikan karakteristik utama dari kepribadian sebuah karakter.

11. Exaggeration

Exaggeration yaitu gerakaan pengembangan dari gerakan normal. Namun, gerakan itu sebaikanya tetap berpandu an pada gerakan natural yang dilebihlebihkan. Gerakan dibuat akan menimbulkan kesan yang mendukung cerita animasi.

12. Soild Drawing 
Soild Drawing yaitu rasa tentang cara pandang tiga dimensi terhadap penokohan seorang karakter goresan garis, shading serta warna.

\section{Kampanye Sosial}

Rogers dan Storey (1987) mendefinisikan kampanye sebagai "serangkaian tindakan komunikasi yang terencana dengan tujuan untuk menciptakan efek tertentu pada sejumlah besar khalayak yang dilakukan secara berkelanjutan pada kurun waktu tertentu" (Venus, 2004:7).

Tujuan kampanye sosial adalah untuk menumbuhkan kesadaran masyarakat akan gejala-gejala sosial yang sedang terjadi. Media kampanye sosial di sini merupakan media pembelajaran yang menjadi alat, sarana, perantara, dan penghubung untuk menyebar, membawa atau menyampaikan sesuatu pesan (message) dan gagasan. Tujuannya adalah untuk merangsang pikiran, perasaan, perbuatan, minat serta perhatian siswa sehingga terjadi proses belajar mengajar dalam diri siswa. Dalam media pembelajaran terdapat dua unsur yang terkandung, yaitu (a) pesan atau bahan pengajaran yang akan disampaikan atau perangkat lunak, dan (b) alat penampil atau perangkat keras. Sedangkan sumber belajar (learning resources) adalah semua sumber baik berupa data, orang dan wujud tertentu yang dapat digunakan oleh siswa dalam belajar, baik secara terpisah maupun secara terkombinasi sehingga memper mudah siswa dalam mencapai tujuan belajar atau mencapai kompetensi tertentu. Sumber belajar adalah bahan-bahan yang dimanfaatkan dan diperlukan dalam proses pembelajaran, yang dapat berupa buku teks, media cetak, media elektronik, narasumber, lingkungan sekitar, dan sebagainya yang dapat meningkatkan kadar keaktifan dalam proses pem belajaran. Dengan penjelasan diatas maka dipilihlah animasi stop motion sebagai media utama kampanye pengenalan tertib berlalulintas bagi remaja pengendara sepeda motor.

Kampanye pengenalan tertib lalu lintas ini bertujuan untuk memberikan informasi pada para remaja tentang cara berkendaraan yang aman sesuai tata tertib berlalulintas yang berlaku, sehingga pelanggaran dan angka kecelakaan lalu lintas dapat dikurangi, untuk mencapai tujuan tersebut dibuatlah media audio visual dalam bentuk stop motion, yang pada prosesnya melewati beberapa tahapan diantaranya pembuatan naskah dan storyboard sebagai acuan durasi, angle, dan efek yang akan digunakan dalam video tersebut.

Kriteria naskah :

1. Singkat, padat dan sederhana

2. Naskah seperti teks berita, singkat dan tepat, berirama, namun mudah di ingat.

3. Naskah tidak harus berupa kalimat lengkap, tetapi berisi kalimat penting yang berkaitan dengan target sasaran.

4. Hindari istilah teknis.

5. Menggunakan kalimat aktif.

6. Usahakan agar tidak melebihi 15 kata dalam satu kalimat, dan durasi maksimal 10 detik untuk satu kalimat.

Kutipan naskah dialog "Sisi Jalan"

(lokasi rumah sakit)

Kiki (remaja): Aduuuhhh... Dimana Aku..??

Dokter : Tenang kiki kamu berada dirumah sakit.

Kiki : Apa yang terjadi padaku?

Dokter : Beryukurlah kamu tidak mengalami luka yang serius, ingatlah nak hidup cuma sekali, maka berhati-hatilah.

Kiki : ya saya ingat dok, kemarin saya berulang tahun, orangtua menghadiahkan sepeda motor untuk pergi ke sekolah.

(muncul polisi )

Polisi : Kamu belum punya SIM, ngebut, dan mengendarai motor dengan ugal-ugalan. kamu menerobos lampu merah dan akhirnya...

Kiki : diam tertegun

Polisi : Taukah kamu bahwa berkendara itu harus mengetahui rambu-rambu yang ada..? jika kamu mengendarai motor, harus mengerti safety riding. Memakai helm, sarung tangan, sepatu dan jaket.

Kiki : menggeleng 
Polisi : Akibat melanggar lalulintas itu bisa terkena sanksi pidana, atau denda uang jutaan rupiah?

Ada baiknya pergi kesekolah bisa menggunakan angkutan umum. Jadi mulai sekarang, "Stop Pelanggaran! Dan Tanya pada dirimu Sudah tertibkah kamu?"

Tahapan pembuatan storyboard adalah:

Menetapkan jenis visual yang akan digunakan dengan pembuatan sketsa terlebih dahulu kemudian menentukan konsep audio yang akan di tampilkan. Audio dapat berupa musik, backsound, musik, narasi, maupun soundeffect khusus.

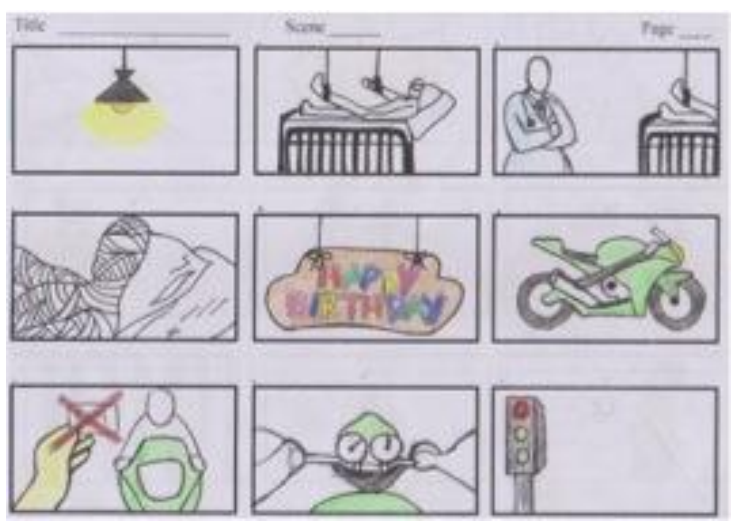

Gambar 5. Storyboard sisi jalan 1. ilustrasi : Reggy Natanael

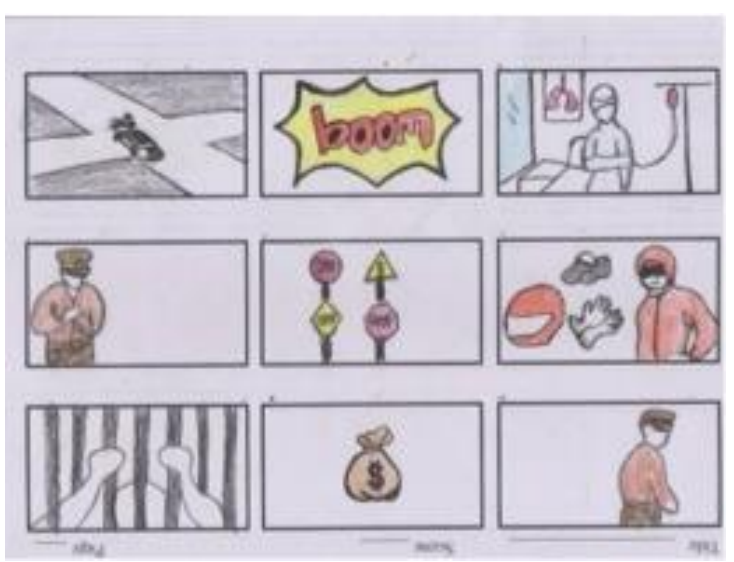

Gambar 6. Storyboard sisi jalan 2. ilustrasi : Reggy Natanael

Setelah storyboard selesai dibuat maka tahapan selanjutnya adalah proses rough design yaitu penggambaran dan pe nyempurnaan karakter maupun obyek yang ada pada narasi. Karakter dan tokoh animasi stop motion dalam kampanye
Pengenalan Tertib Berlalu Lintas bagi Remaja Pengendara Sepeda Motor.

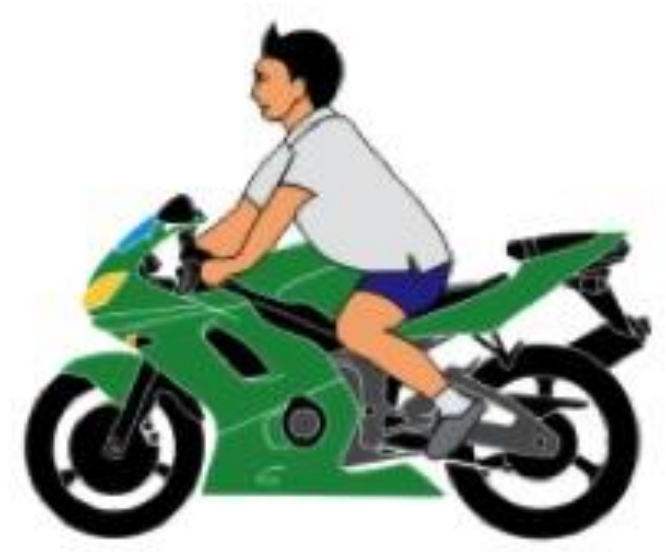

Gambar 7. Tokoh Kiki 1. ilustrasi oleh Reggy Natanael

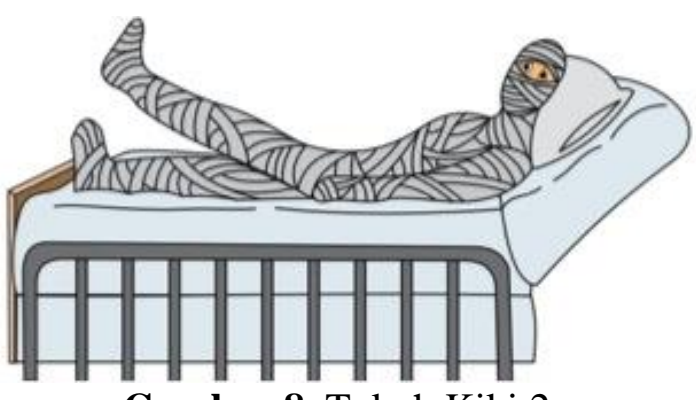

Gambar 8. Tokoh Kiki 2. ilustrasi oleh Reggy Natanael

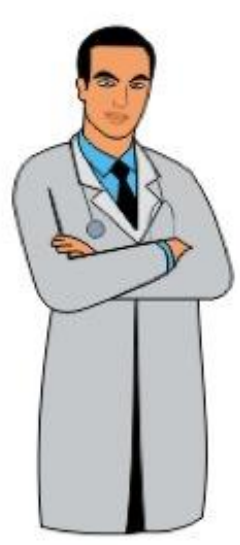

Gambar 9. Tokoh dokter. ilustrasi oleh Reggy Natanael

Setelah tahapan ini selesai maka dilanjutkan dengan tahapan printing dan cutting tiap karakter yang ada dalam animasi stop motion 


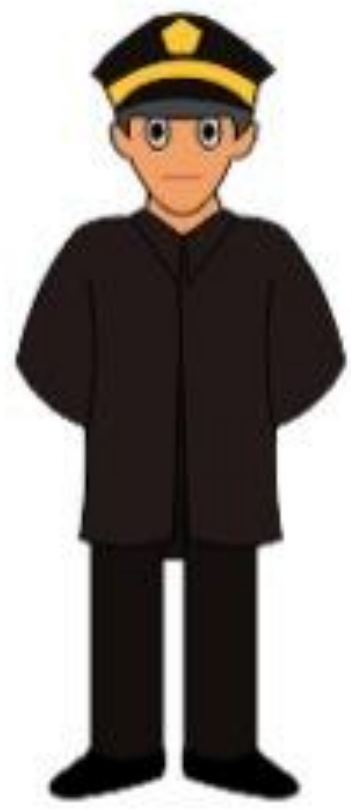

Gambar 10. Tokoh polisi. ilustrasi oleh Reggy Natanael

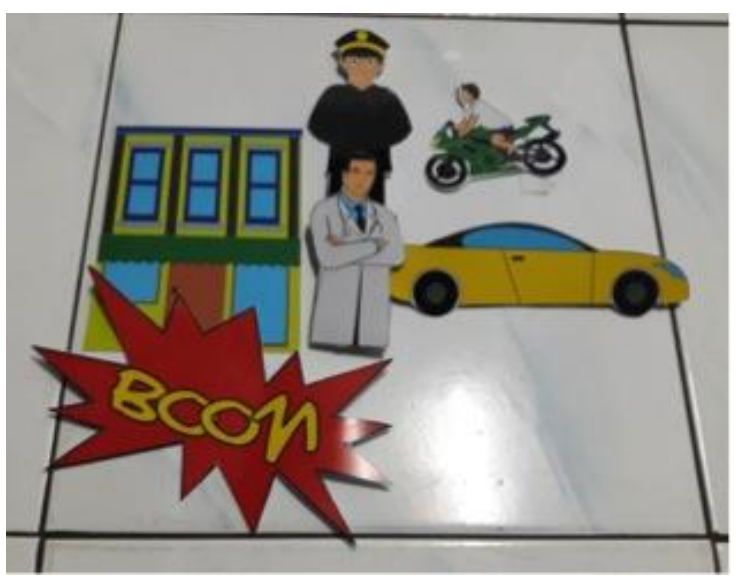

Gambar 11. Tahapan cutting karakter.

Tahapan selanjutnya adalah mempersiap kan sesi foto dengan alat studio mini. Foto yang di ambil merupakan bentuk media cetak yang di animasikan lewat beberapa gerakan dan juga angle yang menarik. Pada tahap ini juga dipersiapkan background pendukung yang disesuaikan dengan adegan yang akan diambil. Untuk satu scene animasi dapat dilakukan beberapa kali shoot foto, sehingga menghasilan suatu animasi yang berkelanjutan.

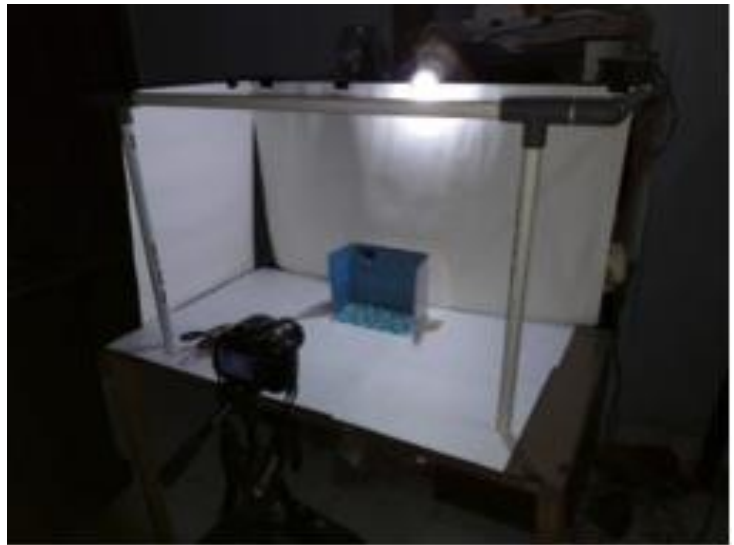

Gambar 12. Peralatan mini studio untuk sesi foto.

Sound, audio atau suara merupakan kesan rasa yang dapat di berikan kepada indra pendengaran pada sebuah sebuah film. Tujuan dari ditambahkannya suara adalah untuk melengkapi suasana yang terjadi dalam suatu adegan yang sedang berlangsung. Suara yang di berikan dapat melalui beberapa tahap, mulai dari mixing sound effect digital, hingga ke tahap recording suara.

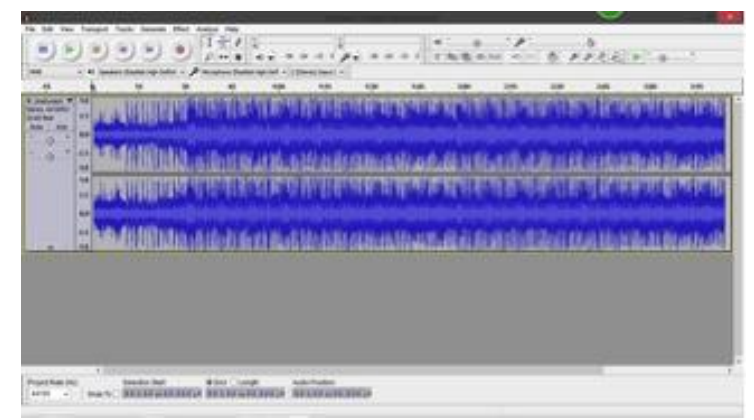

Gambar 13. Tahapan recording audio.

Tahap selanjutnya adalah Compositing yang merupakan bagian penyusunan setiap komponen menjadi satu kesatuan, sehingga membentuk satu animasi yang berisikan gambar dan suara. Proses ini merupakan proses akhir dari tahapan pembuatan video animasi stop motion. Gambar, suara dan video effect disatukan lewat hasil rendering. 


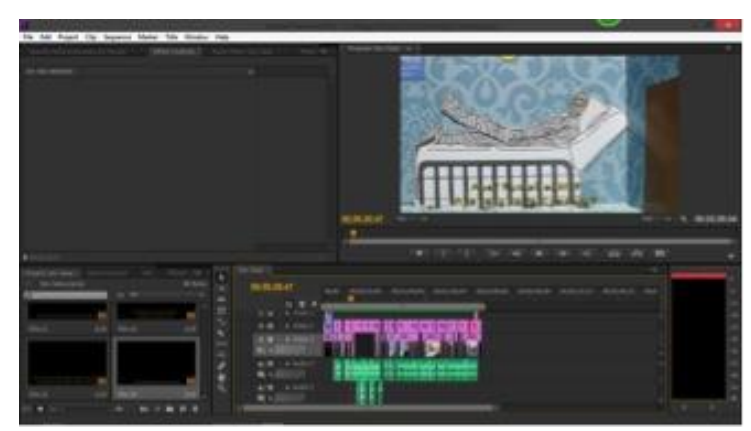

Gambar 14. Tahapan compositing.

Hasil akhir ditunjukkan dalam Gambar 15.

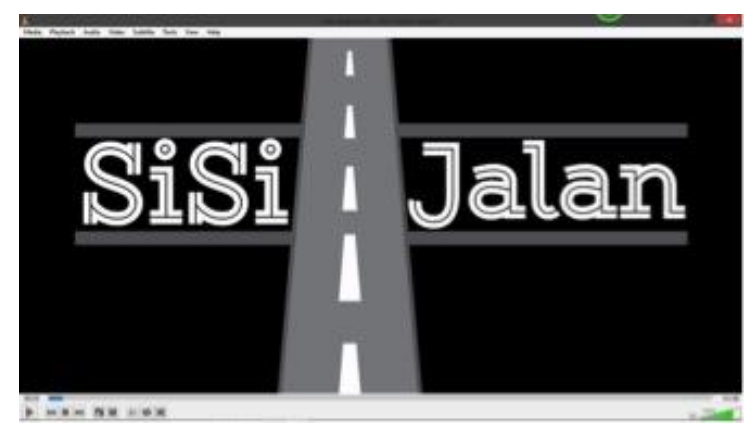

Gambar 15. Opening animasi.

\section{KESIMPULAN}

Perancangan video animasi ini di ciptakan sebagai alternatif media informasi tentang etika ketaatan dan kedisplinan dalam berkendara khususnya sepeda motor untuk remaja. Mengingat kampanye tertib lalu lintas yang telah ada umumnya hanya berupa spanduk - spanduk berisi slogan dan himbauan sehingga kurang mendapat perhatian khususnya bagi remaja.

Dengan konsep animasi stop motion, remaja dikenalkan tentang informasi tertib berlalulintas melalui gaya yang imajinatif dan menarik, tujuannya agar setiap informasi yang disampaikan diharapkan dapat menarik perhatian remaja dan mampu di serap target sasaran dengan baik.

Kampanye sosial ini diadakan sehubungan dengan kurangnya kepedulian terhadap sesama pengendara dijalan raya, dan meningkatnya angka pelanggaran dalam masalah lalu lintas. Hal ini perlu di cegah sejak dini, mengingat mereka yang saat ini belum cukup umur akan menjadi dewasa dan menempati posisi yang sah sebagai pengendara bermotor suatu saat nanti.

Diharapkan kampanye ini dapat diaplikasikan pula di wilayah pinggiran kota lainnya di Indonesia. Sehingga angka pelanggaran lalu lintas di jalan raya bisa semakin berkurang dengan membangun kesadaran pengguna jalan untuk menghargai sesama pengendara di jalan raya.

\section{DAFTAR PUSTAKA}

1. Doellah, H. Santosa, 2002, Batik: Pengaruh Zaman dan Lingkungan, Solo, Danar Hadi.

2. Hamalik, O., 2013, Proses Belajar Mengajar, Jakarta, Bumi Askara

3. Noor, A., 2009, Event Management, Bandung: Alfabeta.

4. Poerwadarminto, W.J.S., 2013, Kamus Besar Bahasa Indonesia, Jakarta, Kemdikbud

5. Rumini, S., Sundari, S., 2004, Perkembangan Anak dan Remaja, Jakarta, PT. Asdi Mahasatya

6. Ruslan, R., 1997, Kiat dan Strategi Kampanye Public Relations, Jakarta, PT Raja Grafindo Persada.

7. Williams, R., 2001, The AnimatorSurvival Kit, United States, Faber and Faber

8. Wright, J.A., 2005, Animation Writing and Development, Burlington, Elsevier Inc. 